\title{
Artelogie
}

Recherche sur les arts, le patrimoine et la littérature de l'Amérique latine

17 | 2021

Transformaciones en Cuba contemporánea: cultura y sociedad

\section{Los archivos de la censura: represión literaria en la Unión Soviética y en Cuba}

Damaris Puñales Alpízar

\section{(2) OpenEdition}

\section{Journals}

Edición electrónica

URL: https://journals.openedition.org/artelogie/10060

DOI: 10.4000/artelogie.10060

ISSN: $2115-6395$

Editor

Association ESCAL

Referencia electrónica

Damaris Puñales Alpízar, «Los archivos de la censura: represión literaria en la Unión Soviética y en Cuba», Artelogie [En línea], 17 | 2021, Publicado el 27 septiembre 2021, consultado el 14 septiembre 2022. URL: http://journals.openedition.org/artelogie/10060 ; DOI: https://doi.org/10.4000/artelogie. 10060

Este documento fue generado automáticamente el 14 septiembre 2022

All rights reserved 


\title{
Los archivos de la censura: represión literaria en la Unión Soviética y en Cuba
}

\author{
Damaris Puñales Alpízar
}

\begin{abstract}
...en aquellos tiempos difíciles, la justicia fue anulada y sustituida por la lógica simplificada de

la racionalidad revolucionaria, sencilla y clara

como un puño.

V. Shentalinski.
\end{abstract}

1 En el 2007 aparecieron en España dos obras que, aunque desde ángulos, geografías y posturas narrativas diferentes, trazan el camino de la censura literaria de dos países y sistemas sociopolíticos que compartieron más de una similitud. Se publicaban en ese año la traducción al español de un libro sobre los archivos literarios del KGB, Crimen sin castigo, del ruso Vitali Shentalinski, y La fiesta vigilada, del cubano Antonio José Ponte. Y aunque pudiera parecer descabellado comparar obras tan disímiles, este ensayo busca en realidad establecer, más que un diálogo, un contrapunteo entre los mecanismos de represión literaria implementados en la Unión Soviética y en Cuba, tomando como punto de partida principalmente la literatura censurada de la que dan cuenta los dos libros mencionados. También tendremos en cuenta otros dos publicados unos años después: Villa Marista en plata, de Ponte, del 2010, en España, y Palabras amordazadas, de Amir Valle, del 2016, en Holanda. Estas obras vienen a complementar las pistas ofrecidas en La fiesta vigilada acerca de las prácticas de censura literaria en Cuba, y son imprescindibles para nuestro análisis por el recuento pormenorizado que ofrecen de muchas de esas prácticas desde 1959 hasta sus respectivos años de su publicación.

2 Pero partamos de una premisa impostergable: es imposible saber a ciencia cierta si existen, en la Cuba actual, archivos que den cuenta de la literatura censurada y de sus 
autores en el mismo sentido en que existían, digamos, en las antiguas Unión de Repúblicas Socialistas Soviéticas -URSS-, o en la República Democrática Alemana RDA- y, si de existir alguno, sobreviviría a un eventual fin del sistema político que se ha mantenido en el poder desde 1959. Al contrario de las prácticas en la antigua Unión Soviética y en Alemania Democrática, donde se documentaban y archivaban los actos de censura y de espionaje cultural -pensemos, por ejemplo, en la película alemana La vida de los otros (2006, dirigida por Florian Henckel von Donnersmarck) ${ }^{1}$, , en Cuba los aparatos censores buscaron desde el principio no solo eliminar cualquier futura sospecha sobre los procesos de censura y los autores reprimidos, sino sobre todo borrar del mapa literario (oficial) a los creadores considerados disidentes o contrarios a la Revolución. En todo caso, si existiese, se trata de un archivo no disponible en estos momentos.

Pero al margen de si existen o no, como en el caso soviético, carpetas con las pruebas de "la máquina de exterminio" -como lo llama Shentalinski² ${ }^{2}$, hay un cambio importante en la forma del archivo que es necesario tomar en cuenta y que está siendo fundamental para documentar algunas de las evidencias de censura: la aparición y prevalencia de las comunicaciones digitales en Cuba, que ha vuelto visibles y puesto en conocimiento público, como nunca antes, muchas acciones represivas que en años anteriores podían pasar más o menos desapercibidas, o que podían ser "borradas" de la historia con mayor facilidad por las autoridades. El registro digital que va quedando de los acontecimientos más recientes ha modificado tremendamente las formas del archivo, de modo que podríamos hablar, ahora, de que existe un archivo digital vivo, en presente -lo cual no implica, claro está, que no haya muchas otras acciones que queden en cierta secrecía, por una parte; y por otra, que sepamos desde ahora cuál será el destino posible de tal archivo, su supervivencia en el futuro-. Pese a todas las estrategias desplegadas por el gobierno ${ }^{3}$ a este le resulta muy difícil, cuando no imposible, controlar la forma en que se produce, se reproduce y circula tal archivo tanto a nivel nacional como internacional. En este sentido, es válido citar las palabras de Ponte en el prólogo a Villa Marista en plata:

4 Para escribir estas páginas me he valido de mensajes electrónicos que otros se cruzaron, de imágenes captadas in situ por teléfonos móviles ajenos, de grabaciones de audio, y hasta de un expediente de seguimiento policial. Entradas de blogs, frases de Twitter, videos en YouTube, archivos digitalizados... He transcrito diálogos sostenidos por gente a las que ni siquiera conozco, como si mi trabajo fuera el de un escucha secreto. (Ponte, 2014: p.9)

5 De manera bastante similar, el recuento hecho por Amir Valle en Palabras amordazadas toma como fuentes las propias experiencias del autor, sus interacciones con otros escritores, así como la información que ha trascendido de manera más o menos pública respecto a determinados actos específicos de censura y represión en contra de algunos autores y obras. Se trata, en ambos casos, de un archivo exógeno, creado al margen y en contra de las intenciones del gobierno.

Un ejemplo elocuente de los diferentes alcances de la vigilancia estatal sobre la labor escritural es la antología de textos literarios publicada por Enrique del Risco en el 2017: El compañero que me atiende. Desde el título se apunta ya a la relación de control ejercida desde los órganos de poder en Cuba que, sin lograr llegar a los niveles de perversidad y precisión de la antigua Unión Soviética o Alemania Democrática, prevén la designación 
de un agente de la policía secreta para vigilar a los intelectuales. Dice del Risco en el prólogo a su antología:

7 ¿Cómo se escribe en un mundo en el que cada escritor, cada ciudadano incluso, tiene un policía secreto de cabecera? La respuesta en el caso cubano está en cada libro escrito en la isla a partir de 1959, en cada compromiso estentóreo, en cada silencio, según lo que imponga el momento. (del Risco, 2017: p.11)

8 Y aunque no se trata, como bien apunta del Risco, de "un memorial de agravios", los textos reunidos en su antología demuestran "exhaustivamente que la vigilancia y la atención de los compañeros no solo han infundido temores de todo tipo en los escritores patrios sino también una profusa y variada creatividad" (del Risco, 2017: p. $25)^{4}$.

Otras diferencias que no pueden tampoco pasarse por alto al intentar este contrapunteo entre las prácticas de censura en los dos países son las existentes en cuanto a historia, dimensiones geográficas y culturales, y liderazgos políticos en cada uno de ellos. De manera definitiva fueron estas diferencias las que establecieron las formas en que se activaron los mecanismos de represión y censura en uno y en otro país, así como las maneras de archivar tales prácticas.

Al ofrecer una definición del archivo, Diana Taylor afirmaba que :

the archive exceeds the 'live.' There are several myths attending the archive. One is that it is unmediated -that objects located there might mean something outside the framing of the archival impetus itself. What makes an object archival is the process whereby it is selected for analysis. Another myth is that the 'archive' resists change, corruptibility, and political manipulation. (Taylor, 2007: p.19)

11 Para Taylor, por otra parte, el repertorio "enacts embodied memory: performances, gestures, orality, movement, dance, singing -in short, all these acts usually thought as ephemeral, nonreproductible knowledge [...] The repertoire requires presence: people participate in the production and reproduction of knowledge by 'being there,' being a part of the transmission" (Taylor, 2007: p.20). Como bien señala Taylor, estas dos formas de transmisión del conocimiento no funcionan por separado. En el caso cubano, además, asistimos a una superposición de ambas funciones al no existir (o al menos al no ser de dominio público) un archivo de la censura en términos taylorianos.

\section{Parte uno: La trilogía del horror}

A fines de los años ochenta, existiendo todavía la Unión Soviética, el poeta y periodista soviético Vitali Shentalinski pidió acceso a los archivos de los escritores que habían sido censurados, encarcelados y/o ejecutados durante el período estalinista. Su objetivo era develar la verdad sobre qué había pasado con los intelectuales rusos que habían sufrido represalias por parte del gobierno. La comisión que se formó, gracias al empuje de Shentalinski, tuvo el mérito de abrir por primera vez los archivos literarios del KGB, y rescatar manuscritos y otros documentos relacionados con esos escritores. Crimen sin castigo es la última entrega de la trilogía escrita por Shentalinski a partir de su pesquisa en esos archivos. Los dos primeros volúmenes fueron Esclavos de la libertad ${ }^{5}$ y Denuncia contra Sócrates ${ }^{6}$, que aparecieron en español en marzo y octubre del 2006, respectivamente, por Galaxia Gutenberg, la misma editorial que publicara el tercer volumen. En la trilogía, Shentalinski rescata las voces de autores que fueron censurados y ejecutados durante los años más cruentos de la represión literaria y política en la 
Unión Soviética, y reconstruye tanto los procesos como las vidas de esos autores. $\mathrm{Al}$ final del tercer volumen, el autor ofrece un listado de 127 autores ejecutados entre marzo de 1937 y octubre de 1938, los llamados años del gran terror o purga estalinista ${ }^{7}$, y ofrece un índice onomástico de todos los mencionados en los tres tomos de la trilogía. Se estima que unas 750 mil personas fueron ejecutadas tan solo en esos dos años, y más de un millón fue enviado a los campos de trabajo forzado de las Gulags ${ }^{8}$.

13 A través de los tres volúmenes, Shentalinski se ocupa de reconstruir fragmentos de la vida de unos pocos autores, imposibilitado de recuperar fragmentos y escenas de los cientos y miles de escritores que engrosaron los archivos del KGB.

Un dato interesante, y muy decidor, que ofrece Shentalinski, es el siguiente: según el censo general de la población de 1937 en la URSS $^{9}$, en ese año solo el 4.3\% de la población había cursado enseñanza secundaria y el $0.6 \%$, estudios superiores.

"Entre los dirigentes de todos los ámbitos sólo la quinta parte podían jactarse de poseer estudios superiores, y el $20.7 \%$ ni siquiera contaba con estudios secundarios ni los cursaban en ese momento [...] En conjunto, un país oscuro y mísero [...] Las raíces del terror psicológicas y civilizadoras se hunden en la ignorancia elemental". (Shentalinski, 2007: p.406-407)

Desde esta perspectiva, puede interpretarse la purga intelectual no solo como la búsqueda del afianzamiento del poder político por parte de Stalin y sus seguidores sino también como una batalla contra la ilustración y el conocimiento, contra la inteligencia y el libre pensamiento, encabezada por el propio Stalin, quien al decir de Shentalinski fue "un poeta frustrado; en su juventud tuvo unos lamentables escarceos en el campo de la poesía" (Shentalinski, 2007: p.414).

16 La persecución y represión no eran solo visibles a través de las muertes en cárceles y campos de trabajo. El recuento hecho por Shentalinski a lo largo de los tres tomos es mucho más exhaustivo, profundamente doloroso:

A otros los asesinaban en secreto, desaparecían sin dejar huella. Murieron por las privaciones y la miseria, acosados por las enfermedades, sin posibilidad de cura. Locura, suicidio, borracheras [...] Lo pernicioso para tantos otros fue el destierro de la patria, la emigración forzada, la privación de la tierra natal y el elemento de la lengua. (Shentalinski, 2007: p.415).

17 La borradura iba más allá de la cuestión física: se hacía desaparecer también la obra literaria, la historia de vida intelectual, y aunque muchos escritores no eran perseguidos, encarcelados o asesinados, terminaban en el más completo ostracismo. Las obras literarias también eran torturadas: "libros inacabados, destinos sesgados y mutilados" (Shentalinski, 2007: p.415).

18 A la hora de armar los procesos en contra de los intelectuales, a cada expediente se le asignaba un número de caso, y cada uno podía ocupar varios tomos, o lo que es lo mismo, "montañas de papeles" (83) conformadas por "resoluciones, actas de interrogatorios y registros, informes, cartas, poemas, fotografías, certificados, recibos, direcciones [...] papeleo confiscado durante los registros..." (84). Como demuestra Shentalinski, muchas veces las causas y los expedientes que los acompañaban fueron compuestos de forma rápida, descuidada, hasta el punto en que se incluían documentos que no tenían relación con el caso ni con la persona. Al reconstruir los últimos momentos de la vida del poeta Leonid Kanneguíser ${ }^{10}$, tras revisar su expediente en los archivos del KGB, Shentalinski afirma:

La causa se compuso a toda prisa, caóticamente. Fue instruida por personas casi analfabetas, cuya competencia jurídica, cuyos conocimientos poco importaban 
puesto que fueron sustituidos por criterios que privilegiaban su gran capacidad como "bolcheviques". En general, en aquellos tiempos difíciles, la justicia fue anulada y sustituida por la lógica simplificada de la racionalidad revolucionaria, sencilla y clara como un puño. (Shentalinski, 2007: p.84)

\section{$1921^{11}(268)-$.}

20 Uno de los autores rusos más reconocidos de todos los tiempos, Isaac Babel, ofrece, en su declaración ante los comisarios políticos, una interpretación que, si bien pareciera ser una confesión forzada de arrepentimiento, deja ver entrelíneas una voluntad de desenmascarar a futuro lo que estaba aconteciendo. Dice Babel en el texto que rescata Shentalinski en Esclavos de la libertad:

...he comprendido que mi argumento, que será útil para muchos, es el autodesenmascaramiento, un relato verídico, artístico y despiadado de la vida de una persona «buena» durante la Revolución. Con este argumento, y por primera vez, he avanzado en mi tarea. No lo he terminado. Su forma ha variado y ha adoptado la de las actas de la instrucción judicial... (Shentalinski, 2006: p.57)

21

Como bien señala Shentalinksi, "las actas judiciales se convirtieron en su forma de expresión... borradores de esa tragedia de la Revolución que nadie había plasmado aún" (58). El acceso a estos archivos nos permite conocer esa tragedia a partir de los testimonios de muchos de quienes la sufrieron y fueron sus víctimas reales.

\section{Parte dos: El archivo incontrolado}

En contraste, La fiesta vigilada traza una ruta diferente mediante un equilibrio entre ficción y realidad. Uno de los cuatro relatos que compone el libro tiene a ratos cierto sabor testimonial por los muchos puntos de contacto con la historia real vivida por el autor: el protagonista de esa historia ficticia -titulada "«Nuestro hombre en La Habana» (remix) ${ }^{12 "}$ comparte rasgos con la biografía del propio Ponte: las referencias (no tan) veladas a escritores y conflictos de su generación; sus experiencias al ser expulsado de la Unión Nacional de Escritores y Artistas de Cuba -UNEAC-: ha sido acusado de recibir dinero del extranjero, de ser un espía del enemigo; su salida de Cuba... El libro contiene otros tres capítulos o acápites: "Caja negra de la fiesta"; "Un paréntesis de ruinas"; y "Una visita al Museo de la Inteligencia", que desarrollan los principales ejes temáticos esbozados en la primera parte.

En el último de los capítulos del libro, Ponte cuenta su encuentro con G. -traductor del español al alemán- en Berlín. G. pone ante sus ojos una carpeta que, según Ponte, podría considerarse el motivo único de su visita a Alemania, la verdadera razón de tal visita (214). Esta estupefacción de Ponte ante aquellas "dos gruesas carpetas con tapas de cartulina y sellos oficiales en las tapas" ${ }^{13}$ (214) ofrece el testimonio necesario para entender la relación entre muchos intelectuales y el poder en Cuba: es un atisbo extrapolado a las prácticas de censura en Cuba que son únicamente conocidas por quienes las padecen y algunos otros pocos, pero que no están al alcance del conocimiento público. Un hecho particular añade incertidumbre sobre tal conocimiento en el futuro: la forma del archivo, de este en específico, es muchas veces intangibles, ligero como el aire, incapaz de dejar rastro. 
24 En esta misma parte, Ponte se refiere a Timothy Garton Ash y a su libro The File. A Personal History. Garton es un historiador británico que recorrió parte de los países socialistas del Este a fines de los setenta. Su mayor interés había sido investigar los archivos de la Gestapo en Alemania Democrática. Pero esta actividad levantó las sospechas de la Stasi, y le consignaron un expediente bajo el nombre de "Romeo" había llegado a Berlín oriental en un carro Alfa-Romeo -. Quince años después, una vez que pudo acceder a su propio expediente, Garton se dedicó a buscar a los antiguos colaboradores de la policía secreta, quienes solo eran identificados en los expedientes con seudónimos o nom de guerre. Una y otra vez, Garton corroboró lo mismo: la ausencia de culpa en aquellos que denunciaban, vigilaban, ejecutaban órdenes. La revisión de la trilogía de Shentalinski, así como The File. A Personal History, que le sirve a Ponte como eje para desarrollar la última parte de su libro La fiesta vigilada, ofrece algunas claves en futuro de lo que sucedería en el (muy hipotético) caso de que en Cuba se abrieran los archivos de la censura (si existiesen, si sobrevivieran a un fin real del actual sistema de gobierno cubano): informantes y delatores que fueron, que han sido "obligados, chantajeados" a participar de los ejercicios de delación; oficiales que "solo seguían órdenes" y para quienes su trabajo proveía un marco de seguridad no ya al gobierno ni al país como entes intangibles, sino a la ciudadanía común y corriente; "víctimas honradas" de haber sido vigiladas, censuradas: tales serían las explicaciones que propondrían respecto a su actuación, podemos especular a futuro. Según Ponte, “Timothy Garton Ash recorría el 'Imperio de Nadie' descubierto por Hannah Arendt. Quien se acercara a aquellos hombres en busca de aclaración comprendería que el mal, una vez rebasado, tenía tanta consistencia como una nube" (Ponte, 2007: p.230).

Ponte se refiere, por supuesto, a la experiencia de Arendt al asistir al juicio del nazi Adolf Eichmann en Jerusalén en 1961, quien fue encontrado culpable de 15 cargos criminales y luego ejecutado en la horca el 1 de junio de $1962^{14}$. Es precisamente en su libro Eichmann en Jerusalén, del año 1963, en el que Arendt acuña la frase "la banalidad del mal" para describir a Eichmann. La frase, controversial en extremo, no apunta sin embargo a que los crímenes cometidos por los regímenes totalitarios sean banales, sino a la ausencia de culpa con que actúan quienes ejecutan acciones para preservar el orden de las cosas en tales regímenes.

Hay otro aspecto que es necesario considerar a la hora de (re)pensar la censura, y la forma en que se archivan los actos de censura en un país como Cuba. Antes apuntábamos al archivo digital vivo que, a día de hoy, constituye la evidencia más clara y concreta -la única tal vez- de la preservación y difusión de los actos de censura por parte del gobierno cubano. Y apuntábamos también a la incertidumbre sobre la existencia de un archivo como el del KGB o de la Stasi, a partir de las evidencias proporcionadas por Antonio José Ponte y Amir Valle en los libros a los que nos hemos venido refiriendo a lo largo de este trabajo. El otro aspecto que nos importa para pensar la posible existencia de un archivo de la censura en Cuba está relacionado con las tesis que sobre el caos y la antropología del subdesarrollo elaboraron respectivamente Antonio Benítez Rojo en La isla que se repite, y Edmundo Desnoes en Memorias del subdesarrollo, cuya conexión es mucho más profunda de lo que podría parecer a simple vista. Si para Benítez Rojo el Caribe no es un mundo apocalíptico. La noción de apocalipsis no ocupa un espacio importante en su cultura. Las opciones de crimen y castigo, todo o nada, de patria o muerte, de a favor o en contra, de querer es poder, de honor o sangre, tienen poco que ver con la cultura del Caribe; se trata de proposiciones 
ideológicas articuladas en Europa que el Caribe sólo comparte en términos declamatorios, mejor, en términos de primera lectura. (Benítez Rojo, 1989: p.xiii-xiv)

para Desnoes, por su parte,

Cada uno se remite a su propia individualidad cuando quiere alejarse de la miseria ajena que (cree) inmerecidamente lo contamina, o se sumerge en el grupo indiferenciado cuando tiene que ocultar su propia responsabilidad y contamina entonces sin empacho a los otros. No hay, entre ellos, en el sentido ético, una sola personalidad moral; no hay uno solo que pueda hacerse cargo de su acción y extender su sentido hasta reencontrar en ella la significación de los actos emprendidos en común. (Desnoes, 1975: p.17)

Y en otro pasaje añade:

Esa es una de las señales del subdesarrollo: incapacidad para relacionar las cosas, para acumular experiencia y desarrollarse... La gente no es consistente y siempre necesitan de alguien que piense por ellos. (Desnoes, 1975: p.44)

Según ambas formas de entender al ser caribeño, o cubano en particular, ninguna política de censura o vigilancia es totalmente efectiva ni totalmente definitiva en Cuba, y no puede ser comparada a la disciplina y el accionar metódico de otros sistemas como el soviético o el alemán, por más intentos que se hayan hecho de copiarlos. No puede contarse, entonces, con la eficacia de un sistema de archivo de la censura para hacer el recuento de estas prácticas en Cuba desde 1959 hasta la fecha, aunque los testimonios de los escritores censurados y exiliados sí den cuenta de los mecanismos represores puestos en marcha y ejecutados desde inicios de la Revolución.

31 Esta incertidumbre respecto a los archivos de la censura, sin embargo, no es privativa de un país caribeño y subdesarrollado como lo es Cuba. En marzo del 2018 el novelista húngaro Andras Forgach relataba, en un artículo titulado "My Mother was a Cold War Spy" que, a diferencia de otros países de la ex cortina de hierro, en particular Alemania del Este, en Hungría se hicieron pocos esfuerzos para indexar los archivos de la censura: "All the dominant political forces are very happy about that. They destroyed a lot. They stole a lot. They used some for blackmail, but most of it is gone ${ }^{15}$."

Pero volvamos momentáneamente a una parte que nos interesa: un espía al servicio de intereses extranjeros. Fue esta misma acusación la que pesó en contra de miles de intelectuales soviéticos, muchas de cuyas voces rescata Shentalinski en su monumental trilogía. Al igual que muchos de esos intelectuales soviéticos, y otros tantos cubanos, el protagonista de Ponte -y Ponte mismo- tuvo que salir a un exilio forzado, acusado de ser él mismo un espía.

Esta novela de Ponte es el preludio de un ensayo que publicaría en 2010, Villa Marista en plata. En ese ensayo posterior el autor profundiza en cómo la represión política y la censura artística se han convertido en el tema central de muchos autores contemporáneos, y en las discusiones de escritores y artistas en torno a la censura.

El nombre de Villa Marista ha sido, sigue siendo, el fantasma que ha impulsado mecanismos de autocensura en muchos intelectuales cubanos. La triste recordación del caso Padilla, el encarcelamiento del poeta durante poco más de un mes (entre marzo y abril de 1971) en ese sitio, y los procesos de condena pública, autoinculpación, ostracismo y luego borradura de la historiografía literaria nacional oficial, sirvieron en su momento de ejemplo público a muchos intelectuales respecto a lo que podría pasarles si osaban desafiar el poder del gobierno. 

censores del gobierno cubano, sino que parte de sus propias experiencias y de la de conocidos y amigos, hay otros dos factores que afianzan el diálogo entre los libros que venimos analizando: tanto Shentalinski como Ponte se refieren, desde sus respectivos ámbitos, a la muerte civil de muchos autores que, al no adaptarse a las condiciones impuestas por el poder ven anuladas sus existencias como intelectuales y tienen que optar por el ostracismo o por la renuncia total a la literatura para sobrevivir económica y físicamente. Dice Ponte al referirse a uno de los escritores analizados por él en un ensayo anterior (aunque no lo nombra directamente, se trata de Virgilio Piñera):

Retirada su obra de todas las bibliotecas y librerías del país, ausente su nombre de los programas de estudio de literatura en institutos y universidades, prohibida toda representación de sus piezas dramática (sus estrenos habían subido a escena en los teatros habaneros más importantes), a los sesentaitantos años quedaba condenado a ganarse la vida como traductor.

(También en Moscú habían dejado a Boris Pasternak esa oportunidad. La traducción literaria es la migaja del oficio que resta a los escritores castigados. Despojados de palabras propias, les permiten salida de ventrílocuos.) (Ponte, 2007: p.32)

El segundo factor en el que coinciden ambos autores es el de la invisibilidad o minimización que muchos autores censurados, exiliados, o sentenciados sufren.

Un ejemplo que ilustra perfectamente la (pretendida) minimización de autores incómodos para el sistema socialista, es precisamente el de Boris Pasternak, quien había ganado el Premio Nobel de Literatura en 1958, pero había sido forzado por el Partido Comunista a renunciar a él. En una entrevista hecha por Nicolás Guillén para el periódico Hoy el 4 de octubre de 1959 a Boris Polevoi, epítome de la novela del realismo socialista soviético, el poeta cubano le pregunta por Pasternak: "Que ha sido de él? ¿Escribe, murió, está vivo, ha modificado su posición?" (Guillén, 2002: p.228). Y responde Polevoi:

este escritor no tiene ninguna posición [...] es un poeta talentoso [...] comenzó a escribir un trabajo en prosa, muy malo, falto de valor artístico en la forma y calumnioso en el fondo. Pasternak ha ofendido sin razón a los hombres y mujeres del país en que vive [...] su novela ha sido desaprobada por los lectores soviéticos en general, incluyendo a los viejos admiradores del poeta [...] Pasternak goza de buena salud, vive en un espacioso departamento de la capital y disfruta de su espléndida casa de campo. (Guillén, 2002: p.229)

Polevoi se refiere, obviamente, a El doctor Zhivago. Sin embargo, es imposible que el lector soviético conociera la novela: como es harto sabido, la novela fue sacada clandestinamente del país -luego de que ninguna editorial soviética quiso arriesgarse a publicarla- y publicada en el extranjero a través de Giangiacomo Feltrinelli, editor italiano de afiliación comunista (razón por la cual tal vez pensó Pasternak que no tendría problemas en la Unión Soviética). Los Estados Unidos, en su rol en la guerra fría cultural en contra de la Unión Soviética, contribuyeron a convertir la novela en un éxito internacional en el mundo occidental. Aunque la novela circuló clandestinamente en la URSS a través de la samizdat, hubo una fuerte campaña del gobierno en su contra, muy parecida a la desatada desde las páginas de la revista Verde Olivo en noviembre de 1968 en contra de Heberto Padilla, y de la novela Tres tristes tigres, del ya entonces exiliado en Inglaterra Guillermo Cabrera Infante ${ }^{16}$, que tampoco había sido publicado en Cuba.

En este sentido, Pasternak entró en la categoría descrita por Shentalinski de "escritores no leídos, pero sí condenados” (2006: p.273), dentro de la que también se encontrarían 
Ajmátova, Solzhenitsin, Brodsky... Una "inepta retórica cuya sola repetición hiere u ofrece un programa completo para eliminar en masa a los escritores que discrepan [...] clasificados como enemigos de clase y su delito es comparable a una traición en el frente de batalla. Y ya se sabe cuál es la condena por traición" (Shentalinski, 2006: p. 273).

Los títulos de los cuatro libros que nos interesan apuntan a una práctica común: el miedo como política de estado. En el discurso que primero definiría las pautas para la relación entre los intelectuales y el poder político en Cuba, al concluir las reuniones entre Fidel Castro y artistas y escritores cubanos en la Biblioteca Nacional en 1961, Virgilio Piñera diría: "Yo solo sé que tengo miedo, mucho miedo" (Valle, 2016: p.29).

Sobre este miedo del que hablaba Piñera, afirma el escritor y periodista Carlos Victoria respecto al sentimiento que el estado de las cosas provocaba en los intelectuales cubanos,

¿cómo escapar de esa atmósfera de terror que nos rodeaba, de las prohibiciones por simplezas como usar un pantalón campana o llevar pelo largo, de las verdades tragadas por miedo a una delación por desviación ideológica o moral, de las represalias por oír música en inglés o que no fuera la música cubana hecha por cubanos que no habían traicionado, de las llamadas de atención porque una frase dicha o escrita en un cuento o en un verso sonaba rara para los puristas de la ideología, de las torturas en las cárceles y esa humillación de hacerte sentir una no persona?; es una pregunta que ninguno de nosotros ha podido responder convincentemente. (citado por Valle, 2016: p.30)

Tanto la alfabetización como la creación de instituciones culturales y la promoción de publicaciones impulsadas desde el principio de la Revolución fueron un desafío al concepto de la ciudad letrada burguesa, y su objetivo último era no solo crear una población lectora, consumidora de cultura y sobre todo de literatura, sino también crear un ejército de escritores que diera fe y apuntalara la nueva sociedad que se pretendía construir. Esta ciudad letrada, por tanto, estaría signada por exclusiones y limitaciones que se harían efectivas a través de sanciones no escritas de su órgano rector, la UNEAC, para con sus miembros. Pero tales sanciones, tales exclusiones, pasarían sin dejar huella escrita. Al respecto, dice Ponte:

...en adelante ningún trabajo mío podría aparecer en las revistas y editoriales del país, suspenderían cualquier presentación en público que intentara y, ya que no podían controlar mis movimientos en el extranjero, no iba a encontrar ayuda de ninguna institución para afrontar las gestiones migratorias. Me dejaban a solas en el laberinto burocrático. (Ponte, 2007: p.41)

43 Y unos párrafos más adelante, añade que tales notificaciones fueron siempre verbales, de modo que no podría rastrearse nunca ningún documento que llevara al dictamen de la sanción: "No es tradición de la Unión de Escritores ofrecer sus sanciones por escrito" (45), le habían dicho sus interlocutores cuando fue expulsado de la ciudad letrada oficial que es la UNEAC:

Yo tendría que apelar por escrito a una sanción hecha en el aire (...) Al parecer, la institución blanqueaba desde ya sus archivos. Cualquier investigador futuro, por suspicaz que fuera, podría revisar la documentación salvaguardada en aquel edificio. (46)

Estas declaraciones de Ponte nos sitúan frente a otra pregunta para la que tampoco tenemos respuesta por ahora: ¿existe una única institución que sea la encargada de regir y controlar todo lo referente a la producción cultural de manera que se garantice aquello de "Dentro de la Revolución, todo; contra la Revolución, nada"? O, ¿cada 
institución -entiéndase Instituto Cubano de Arte e Industria Cinematográfica, Instituto Cubano de Radio y Televisión, Ministerio de Cultura, Instituto Cubano del Libro, etc. -, era/es responsable de crear y mantener sus propios expedientes de la censura, aplicar sanciones, controlar la producción cultural de sus respectivas áreas?

Pese a las diferencias, el paralelo entre las obras de Shentalinski y de Ponte corre a niveles mucho más profundos, y también, mucho más mundanos, incluso anecdóticos: cuenta Ponte en una entrevista ${ }^{17}$ que siendo Abel Prieto Ministro de Cultura le envió un recado a través de varios conocidos comunes: "Díganle a Ponte que él no va a ser Brodsky" ${ }^{18}$.

Pese a los detalles autobiográficos y el innegable sabor ensayístico de La fiesta vigilada, no se puede subestimar su condición de novela, algo de lo que tan bien nos advierte Ibrahim Hernández Oramas al conversar con Ponte en la entrevista recién referida; tampoco podemos confundir del todo a su personaje principal con el autor, aunque por ratos, muchos, parezca este un alter-ego de aquel. En esa misma conversación, Ponte reconoce "el lastre ensayístico" con que carga esa novela suya. Sin embargo, hace una acotación:

yo no estaría inclinado a considerar ingenua una lectura que confunda la voz que narra en ella con el propio autor, conmigo mismo. Es cierto que el Marcel narrador en En busca del tiempo perdido no es Marcel Proust, pero tendríamos que aceptar con bastante probabilidad que el Michel de Ensayos es Michel de Montaigne. Y quien habla en La fiesta vigilada es más Michel que Marcel. Pero puedo estar equivocado al respecto, puedo estar entendiendo pésimamente eso que he escrito.

Pero vuelvo a La fiesta vigilada, porque junto a la coincidencia de ciudades entre la que vivo y la de la novela de Greene, hay otra coincidencia más: las autoridades culturales del país me acusan (tengo claro el recuerdo de los comisarios Abel Prieto y Carlos Martí diciendo... bueno, ya da igual lo que dijeran sus palabras de comisarios) de estar pagado por los servicios secretos estadounidenses, de ser colaborador de la CIA. Lo cual me hace volver a la comedia de espías ("an entertainment", la calificó Greene, para no considerarla del todo novela) de Our Man in Havana, con Wormold y su red de espías falsa, imaginada para sacar provecho. Otra razón de más para leer con interés las peripecias habaneras de Mr. Wormold.

Esta segunda razón es lo que hace de mi libro, novela o ensayo o quisicosa, también un libro memorialístico. Que habla, como dices, desde un lugar más cercano. (Hernández Oramas, 2018: Web)

\section{Parte tres: Conservar a perpetuidad vs el archivo de aire}

Bajo el rótulo "Conservar a perpetuidad" se archivaban los materiales sobre los autores censurados, torturados, detenidos y/o asesinados durante los años del terror estalinista en la Unión Soviética. Este fue el mismo título que le dio Shentalinski a la sección en la que comenzó a publicar sus hallazgos en la revista Ogoniok (llamarada, chispa, en ruso) en la todavía Unión Soviética de fines de los años ochenta. Fueron estos artículos los que servirían de base al autor para crear la trilogía de la que damos cuenta en este ensayo.

En enero de 1995, decía Shentalinski en un artículo suyo aparecido en El País: 
Los archivos de la Ubianka [sic], que sigo estudiando por quinto año consecutivo, me recuerdan siempre el argumento de un relato fantástico de terror, en el que tras una puerta que da a lo desconocido siempre se abre una segunda puerta, una tercera, y así hasta el infinito. (Shentalinski, 1995: Web)

Desde años atrás, él había estado revisando los archivos de la censura literaria para investigar el destino de escritores que habían sido perseguidos por la policía secreta de Stalin, la NKVD. Poco después comenzó a revisar los archivos del KGB ${ }^{19}$. Estamos hablando, sin embargo, de un trabajo titánico: se estima que, durante el período soviético, unos 3,000 escritores fueron represaliados de un modo $u$ otro. $Y$, aproximadamente, la mitad pereció en los campos de concentración o, fue fusilada ${ }^{20}$. En total, según el testimonio de Shentalinski, el KGB llegó a completar 200 enormes carpetas rojas con las pruebas de su "máquina de exterminio". Ofrecemos estas cifras no porque sean novedosas: a estas alturas son bastante conocidas y basta con un simple click en google para poderlas encontrar, aunque no por ello dejan de ser escalofriantes. Pero las ofrecemos como testimonio no solo de nuestro propio abatimiento, sino sobre todo porque no logramos imaginar el espanto de Shentalinski y el equipo que tuvo a su cargo ir abriendo aquellas cajas, ir descubriendo lo que hasta entonces eran verdades a medias, sospechas en muchos casos, especulaciones hechas en voz baja en sitios más o menos secretos. ¿Cómo leer las últimas horas de vida de Isaac Babel, ejecutado en enero de 1940, y de tantos otros, exterminados por los caprichos de la política? Lo confiesa el mismo Shentalinski en una entrevista suya, también aparecida en El País:

Cuando abrí por primera vez esos tomos y los expedientes personales no pude evitar cerrarlos de golpe y mirar hacia otro lado. Pero recuperar esta memoria es como mirar los grabados de Goya: doloroso pero necesario. (Marín Yarza, 2007: Web)

53 En el caso cubano, al hacerse un recuento de los primeros años de la Revolución no pueden soslayarse dos hechos que, en diferente medida cada uno, propiciaron "cierta apertura" hacia el arte y la experimentación artística y literaria. Por una parte, los titubeos del gobierno para establecer alianzas con la URSS o con China; por otra, y más importante, el hecho de que la URSS estaba viviendo lo que se ha llamado "el deshielo" del gobierno de Nikita Khrushchev, que propició cierta tolerancia hacia otras formas artísticas diferentes al realismo socialista entre 1956 y 1964 (cuando fue destituido al tradicional estilo soviético de unanimidad partidista), así como la rehabilitación de millones de víctimas de los años de la purga estalinista. La coincidencia de la llegada al poder en Cuba de un grupo de jóvenes y del deshielo soviético estimuló una sinergia de influencias que impulsó, al menos momentáneamente, la producción cultural en ambos países, y también su fin. Tal apertura duró poco, y tan solo dos años después se delineaba, grosso modo, la política cultural de la Revolución cubana con el archiconocido discurso de Fidel Castro en la Biblioteca Nacional. La consecuencia más inmediata y visible de tales políticas fue la salida al exilio de numerosos escritores cubanos: Guillermo Cabrera Infante, Severo Sarduy, Lydia Cabrera, Lino Novás Calvo, Jorge Mañach, Carlos Montenegro, Gastón Baquero, Nivaria Tejera... por solo mencionar algunos pocos. Otros, que se quedaron en Cuba, como Virgilio Piñera, tuvieron que dedicarse a la traducción, y relegar o anular su actividad su creadora y sus publicaciones, como Dulce María Loynaz o José Lezama Lima.

54 Tal vez influenciado por Las palabras a los intelectuales de Fidel Castro, en quienes los soviéticos veían una esperanza para la renovación del socialismo, al inaugurar en Moscú la que se considera la exposición más corta de la historia del arte moderno, 
Nikita Khrushchev arengaba en contra del arte abstracto y sobre el papel del artista en la sociedad socialista. Daba su opinión, y con ella inauguraba y clausuraba al mismo tiempo la primera exposición soviética de arte abstracto. Afirmaba el mandatario el 1 de diciembre de 1962: "Obras como éstas son completamente ajenas al espíritu de nuestro pueblo. Deberían reflexionar sobre ello los individuos que se dicen pintores, pero hacen cuadros que no se sabe si han sido realizados por la mano del hombre o por la cola de un asno"21. La exposición fue clausurada ese mismo día.

55 A nivel público, los discursos de ambos mandatarios establecían los límites imprecisos, incompletos, pero contundentes-, que habrían de contener la producción artística, y prescribían las fórmulas para la relación entre los intelectuales y el poder. La sinergia entre ambos sucesos va más allá: de la misma manera en que Fidel Castro se había reunido con los intelectuales cubanos en la Biblioteca Nacional tras la prohibición de exhibir en las salas nacionales el documental P.M., apenas unos días después de las duras opiniones de Khrushchev sobre el arte abstracto en Moscú, el portavoz del Partido Comunista de la Unión Soviética, Leonid Ilyichev, se reunía el 17 de diciembre de 1962 en el Comité Central con 400 artistas, compositores y escritores para dejar en claro, por si había alguna duda, de que el Partido estaba reevaluando su política de liberalización en las artes y esperaba que la comunidad creativa se adhiriera nuevamente a los principios del realismo socialista. Como en Cuba, los cotos de la censura (y la autocensura) habían sido trazados desde el gobierno.

56 Cuenta Ponte en la última parte de La fiesta vigilada que de visita en Berlín post comunista se estremeció ante el expediente que la Stasi había armado con información sobre su amigo: dos gruesas carpetas gigantescas en la que se conservaba todo el material que la policía secreta de Alemania Oriental había logrado recopilar tras años vigilando a G., el amigo de Ponte. El expediente consistía en tres clases de documentos: correspondencia, transcripciones de llamadas telefónicas, e informes y delaciones de vecinos y conocidos del vigilado.

57 De paso por la barriada de Miramar, en La Habana, podría el paseante ingenuo (o extranjero) dejarse atraer por un cartel que asoma tímidamente entre los frondosos árboles de la quinta avenida: el Museo de la Denuncia ${ }^{22}$. Sin embargo, tal anuncio solo podría confundir a algún visitante despistado, si tal viajero existiera. ¿Qué se denuncia? Definitivamente no los actos del gobierno en contra de sus ciudadanos. Tampoco ninguna medida de censura llevada a cabo en contra de intelectuales o escritores cubanos porque, a los ojos del gobierno la censura, si llegase a ser reconocida públicamente como una realidad, siempre es justificada. Según la información ofrecida en la página web de Ecured ${ }^{23}$, el sitio se enfoca en seis temáticas diferentes, cinco de ellas relacionadas con los efectos de acciones de Estados Unidos hacia Cuba, y una última con obras de arte donde se muestra la participación del pueblo en la Revolución.

En el último capítulo de La fiesta vigilada, Ponte juega con nosotros, lectores despistados, ingenuos, y narra la visita de su personaje/alter-ego al Museo de la Denuncia, y lo que dice al llegar al sitio:

Vengo a saber lo que tienen de mí [...] Me han acusado de pertenecer a una red que opera desde el extranjero. Afirman que esa red recibe mensualidades de la agencia de inteligencia estadounidense. Me consideran becario de la CIA o algo por el estilo, y he sido desactivado de la Unión de Escritores [...]

Se trataba de una petición prematura. (Ponte, 2007: p.234) 


\section{Dan, el primer perro policía que hubo en la Cuba post-1959. En Praga, durante la época} socialista, hubo un museo similar, también con perro embalsamado (Ponte, 2007: p. 236-237). Lo más contundente, según Ponte, fue las conclusiones a las que se podía llegar tras una visita a tal museo cubano: "A juzgar por lo expuesto en el Museo de la Inteligencia, los expedientes secretos no existían" (238). Y de existir, ha habido el tiempo suficiente para pasarlos a archivos digitales, que pueden desaparecer con la rapidez de un golpe de tecla.

61 Es posible, entonces, que a diferencia de lo que le ocurrió a Shentalinski al abrir las carpetas del KGB, ningún futuro indagador del pasado cubano se espante con los expedientes encontrados en los edificios que guarden la memoria de los procesos de censura en contra de los intelectuales en la isla. Sin embargo, esta aparente incoherencia en las formas de ejercer la censura no debe hacernos perder de vista el hecho irrefutable de que esta ha sido una práctica constante en la que solo ha cambiado de expresión el cómo se practica, pero no la práctica de la censura como tal. El mismo Ponte nos da su valoración al respecto cuando habla de la estatua de John Lennon como alegoría de los 'nuevos tiempos' en los que la censura se recubriría de un velo más suave, menos carcelario, pero igualmente eficiente: "Dulce perdón, por fin habían sentado a Lennon en un parque del Vedado. Con parque póstumo le pagaban el silenciamiento de años antes" (Ponte, 2007: p.43).

Uno de los antiguos seguidores de The Beatles en su juventud, entonces clandestino oyente del grupo británico, había sido promotor principal para erigirle una estatua habanera en los nuevos tiempos. Y era el mismo que ahora le comunicaba a Ponte de su expulsión de la UNEAC mientras le ofrecía, de inmediato, un paliativo como muestra de su amistad: podría apelar y las sanciones se levantarían "en dependencia de mi conducta futura" (Ponte, 2007: p.45). La apelación habría que hacerla por escrito; la expulsión solo se hacía de manera oral.

\section{Parte cuatro: Notas para unas (in)conclusiones}

Crimen sin castigo y La fiesta vigilada cuentan la verdad sobre los caminos de la censura desde diferentes lados de la historia: en el primer caso, su autor, Vitali Shentalinski, dedicó varios años a explorar, dolorosa pero meticulosamente, los archivos literarios del KGB, desde fines de la década de los ochenta en la entonces Unión Soviética, y hasta mediados de los noventa, en la actual Rusia, una vez desplomado el sistema socialista; en La fiesta vigilada, Antonio José Ponte ubica al protagonista -que por ratos podría ser confundido con el propio autor- en el lado de la historia donde el gobierno sigue estando en manos del partido único. El personaje solo puede contarnos una verdad que siempre estará incompleta: es a partir de su propia experiencia; los archivos de la censura no han sido abiertos, y lo que es incluso más desconcertante, tal vez tales archivos ni siquiera existan en el futuro. Como dice el narrador en algún momento:

“... la carpeta era pura utilería, no extraerían de ella ningún documento.

«No es tradición de la Unión de Escritores ofrecer sus sanciones por escrito», consideraron mis interlocutores. 
...Yo tendría que apelar por escrito a una sanción hecha en el aire [...] Al parecer, la institución blanqueaba desde ya sus archivos. Cualquier investigador futuro, por suspicaz que fuera, podría revisar la documentación salvaguardada en aquel edificio.

«¿Prohibido ese escritor de que me habla?», llegarían a desentenderse los responsables. «¿Y en cuál papel consta?»

Mi etapa de fantasma comenzaba sin prueba alguna". (Ponte, 2007: p.45-46) profundo de las políticas de censura no tiene que ver únicamente con la prohibición para publicar este o aquel libro, desaparecer a aquel o al otro autor, sino con la creación y perpetuación de mecanismos de autocensura. Al contar las recomendaciones de un editor a quien le llevara un libro suyo de poesía, ya en tiempos de la glasnot a fines de los ochenta, se asombraba Shentalinski de las aprehensiones de éste, respecto a algunas palabras y conceptos que aparecían en sus versos: "Después de décadas de castración espiritual, muchos de esos conceptos no solo fueron eliminados de los textos, sino de las propias conciencias. El censor exterior desapareció, pero quedó el interior, y vencer a este era mucho más difícil" (Shentalinski, 2006: p.10).

comentario de Juan Orlando Pérez, a propósito de la exhibición por primera vez en Cuba de la película Doctor Zhivago ${ }^{24}$ en el 2018 -la película fue producida en 1965-, añade otra perspectiva a los alcances de la censura:

"para ser totalmente efectiva, la censura necesita tiempo, lograr que desaparezca la curiosidad por lo censurado, y que el libro o la película malditos se desgasten lentamente en los corredores de la clandestinidad y en su propia, exagerada leyenda, hasta que, pasados los años, ya no sean dañinos, o no tanto, solo los restos arqueológicos de otra época, una vasija rota sacada del fango de la historia, y no haga falta insistir en su prohibición, se puede permitir que la gente los vea y se queden con el regusto amargo de la decepción." (Pérez, 2018: Web)

Si en el caso soviético/ruso, Shentalinski tuvo la oportunidad de revisar las pruebas dejadas por la "máquina del exterminio", y a través de los archivos de los expedientes armados a los intelectuales vigilados, censurados, apresados y en muchos casos, ejecutados, hacer una disección de los mecanismos del horror, en el caso cubano, vamos viendo, el archivo de la censura se vuelve, muchas veces, inaprehensible: se trata de un archivo de aire, del que no va quedando rastro, empeñados como están los funcionarios del poder en borrar toda evidencia. Va quedando, eso sí, un archivo digital vivo, cuya memoria será fundamental para regresar al análisis de la historia de las últimas décadas de producción cultural en Cuba. Lo más tangible, como hemos dado cuenta en este artículo, es el archivo literario que los autores han creado, usando la ficción como medio.

Pero sería ingenuo pretender comparar el horror. Cada uno es terrible en sí mismo. Único en su extensión, en el daño causado, en las vidas alteradas. Sería, sobre todo, injusto para con las víctimas del horror establecer, intentarlo siquiera, algún tipo de competencia, de emulación socialista de la censura y del espanto. Los libros comentados brevemente aquí tienen su mayor mérito en develarnos esas verdades, ese horror. En impedir que podamos voltear la cara e ignorar estos hechos, incluso aunque no sean, como en el caso de Cuba, públicos del todo. 


\section{BIBLIOGRAFÍA}

Adams, Tim (2018), “Andras Forgach: “My mother was a Cold War spy”. The Guardian. 25 March. <https://www.theguardian.com/books/2018/mar/25/my-mother-was-a-cold-war-spy-hungarynovelist-andras-forgach>.

Aller, Jesús (2009), “Vitali Shentalinski en los archivos de la Lubianka. Represión y literatura bajo el stalinismo”. Nodo50. 31 de julio. <https://info.nodo50.org/Vitali-Shentalinski-en-los.html>.

Armand, Octavio (1980), "Mini discurso para borrar al escritor cubano del exilio". Escandalar 10: p.86-89. < https://incubadorista.files.wordpress.com/2017/03/oarmand.pdf>

Benítez Rojo, Antonio (1989), La isla que se repite. El Caribe y la perspectiva post-moderna. Hanover, CT: Ediciones del Norte.

del Risco, Enrique (2017), El compañero que me atiende. Madrid: Hypermedia.

Desnoes, Edmundo (1975), Memorias del subdesarrollo. México, DF: Joaquín Mortiz.

Díaz Martínez, Manuel (1997), "El caso Padilla: crimen y castigo (recuerdos de un condenado)". Rialta Magazine. <http://rialta-ed.com/el-caso-padilla-crimen-y-castigo/>.

Fernández Pérez, Michel (2019), “Las leyes que vienen, o que deben venir en Cuba”. OnCubaNews 13 de agosto. <https://oncubanews.com/cuba/las-leyes-que-vienen-o-que-deben-venir-en-cuba/ $>$.

Forgach, Andras (2018), "My mother was a Cold War spy." The Guardian. 24 March. <https:// www.theguardian.com/books/2018/mar/25/my-mother-was-a-cold-war-spy-hungary-novelistandras-forgach>.

Garbatzky, Irina (2016), “La fiesta vigilada de Antonio José Ponte. El archivo bajo sospecha”. Cuadernos de Literatura 40, Vol. XX. (Julio-diciembre): p.69-88.

Guillén, Nicolás (2002), “Conversación con Polevoi” (Hoy, 4-X-1959). Prosa de prisa, 1929-1985. Tomo II. La Habana: Ediciones Unión: p.226-230.

Hernández Oramas, Ibrahim (2018), “El acento Ponte. Una conversación”. Rialta Magazine, septiembre. <http://rialta-ed.com/acento-ponte/>.

Logroño, Ernesto (2016), “A Bold Attempt to Redefine ‘Dissidence’ in Cuba”. Repeating Islands. <https://repeatingislands.com/2016/09/04/a-bold-attempt-to-redefine-dissidence-in-cuba/>.

Marín Yarza, Maribel (2007), “Vitali Shentalinski destapa la tercera caja negra del KGB. Crimen sin castigo cierra su estudio sobre la represión de intelectuales en la URSS”. 4 de diciembre. <https:// elpais.com/diario/2007/12/04/cultura/1196722803_850215.html>.

Melo Ruiz, Héctor Alfonso (2017), "Memorias del subdesarrollo (1968): ante el rostro de la muchedumbre desde las paradojas del cine documental." A Contracorriente. Una revista de estudios latinoamericanos. Vol. 15. No. 1 (Fall): p.127-148.

Pérez, Luis Orlando (2018), “Apoteosis de la censura”. El Estornudo, 7 de febrero. <https:// www.revistaelestornudo.com/apoteosis-la-censura/>.

Ponte, Antonio José (2007), La fiesta vigilada. Barcelona: Anagrama.

Ponte, Antonio José (2014), Villa Marista en plata. Arte, política, nuevas tecnologías. Madrid: Hypermedia . 
Shentalinski, Vitali (2006), Esclavos de la libertad. Barcelona: Galaxia Gutenberg.

Shentalinski, Vitali (2007), Crimen sin castigo. Últimos descubrimientos en los archivos literarios del KGB. Barcelona: Galaxia Gutenberg.

Shentalinski, Vitali (1995), "Bábel y las voces y del más allá”. El País, 26 de enero. <https:// elpais.com/diario/1995/01/26/opinion/791074806_850215.html>.

Taylor, Diana (2007), The Archive and the Repertoire: Performing Cultural Memory in the Americas. Durham: Duke University Press.

Taylor, Ella (2017), “In The Documentary 'Karl Marx City,' A Grim But Enlightening Homecoming." NPR.org, March 30. <https://www.npr.org/2017/03/30/521644024/in-thedocumentary-karl-marx-city-a-grim-but-enlightening-homecoming>.

Valle, Amir (2016), Palabras amordazadas. Amsterdam: Eva Tas Foundation.

Wejebe, Cobo Jorge (2018), "El arte abstracto, Nikita Jruschov y la CIA.” Diario90. 6 de junio. <https://www.diario90.com/2018/06/06/el-arte-abstracto-y-la-cia/>.

\section{NOTAS}

1. La película cuenta la historia de una pareja de artistas, un dramaturgo (Georg Dreyman) y una actriz (Christa-Maria Sieland) y la suerte que corren cuando un ministro se encapricha con la chica y comienza a perseguir a Dreyman para sacarlo del medio. A Gerd Wiesler, profesor de técnicas de espionaje, le encargan la vigilancia de Dreyman, pero poco a poco se va transformando y comienza a crear una historia ficticia de Dreyman, y lo salva. (Para una sinopsis y análisis más completo véase Juana la loca: <http://dpalpizar.blogspot.com/2007/06/>, 15 de junio de 2007.)

Por su parte, el documental Karl Marx City, del 2016, dirigido por Petra Epperlein y Michael Tucker, narra el regreso de la primera a su pueblo natal en Alemania, antes llamado Karl Marx y ahora rebautizado como Chemnitz, para tratar de encontrar la verdad respecto al pasado de su padre, suicidado en 1989 tras quemar todos sus papeles. Eppelein y sus hermanos gemelos han sospechado desde entonces que su padre era informante de la Stasi. "The fascinating Karl Marx City, which Epperlein made with her husband Michael Tucker, is as much an inquiry into the mechanics of how autocratic regimes work as it is a search for the truth about one citizen's tragic end in its clutches. As one witness observes drily, if three people were seated together anywhere in the GDR, it was assumed that at least one of them was among the thousands of civilian informants dragooned or blackmailed into service to maintain round-the-clock surveillance for the Stasi. Everyone was suspect, though of what crime mostly remained unclear." (Véase Ella Taylor, NPR.org). El documental es narrado en tercera persona.

2. Véase Marín Yarza, Maribel: "Vitali Shentalinski destapa la tercera caja negra del KGB”, El País 4 dic. 2007: <https://elpais.com/diario/2007/12/04/cultura/ 1196722803_850215.html>

3. Tales estrategias incluyen la creación de la Universidad de las Ciencias Informáticas coincidentemente en el mismo sitio donde antes estuviera ubicada la estación de radioescucha Lourdes, de los soviéticos, entre 1964 y 2001-, que ha graduado a más de 15 mil ingenieros desde su apertura en el 2002; un contingente de "trolls" que refuta y 
contradice cualquier información que pueda dañar la reputación del gobierno cubano aunque la mayoría usa nombres y cuentas falsas en Facebook y otros medios, la cara más visible es Iroel Sánchez-. Por otra parte, la Política de Comunicación Social del Estado y el Gobierno cubanos aprobada en el 2018 establece que "el Partido Comunista de Cuba es rector de la comunicación social en el país, traza la política general para su desarrollo y ejerce su control". Su primer objetivo, dice, es "contribuir a garantizar el consenso y la unidad nacional en torno a la Patria, la Revolución Socialista y el Partido". El documento va mucho más allá al demeritar a los medios independientes, y al dejar en un marco de ilegalidad cualquier actividad informativa que no se ajuste a lo estipulado en la Política. (Para más información véase "¿Qué dice la nueva política de comunicación cubana?". Periodismo de barrio. 2 de diciembre de 2018. <https:// www.periodismodebarrio.org/2018/12/que-dice-la-nueva-politica-de-comunicacioncubana/>.) Mientras tanto, la recién reformada Constitución cubana (abril de 2019) deberá aprobar una ley para regular la libertad de prensa. La Asamblea Nacional del Poder Popular tiene hasta abril del 2020 para aprobar las leyes que le den cuerpo y legalidad a la nueva constitución. El proyecto de ley relacionado con la prensa (que se espera se apruebe por absoluta mayoría) deja en el limbo legal a muchas publicaciones no oficiales, al no definir qué son los "medios fundamentales de comunicación", entre otros entresijos legales. (Véase "Las leyes que vienen, o que deben venir en Cuba". OnCubaNews 13 agosto 2019: <https://oncubanews.com/cuba/las-leyes-que-vienen-oque-deben-venir-en-cuba/>.)

4. Son varios los textos que, desde diferentes perspectivas, han intentado explicar la relación del intelectual y el gobierno cubano post-1959. Además de los glosados en este artículo, sugerimos otros, conscientes de que esta lista no es ni de lejos exhaustiva: de Desiderio Navarro, La causa de las cosas, La Habana: Editorial Letras Cubanas, 2006 y La política cultural del período revolucionario: memoria y reflexión, La Habana: Centro TeóricoCultural Criterios, 2008; de Duanel Díaz, Palabras del trasfondo. Intelectuales, literatura e ideología en la Revolución Cubana, Madrid: Editorial Colibrí, 2010; de Guillermo Rodríguez Rivera, Decirlo todo. Políticas culturales (en la Revolución cubana), La Habana: Ediciones Ojalá, 2017; de Emilio J. Gallardo Saborido, Jesús Gómez de Tejada y Damaris Puñales-Alpízar, Asedios al caimán letrado: literatura y poder en la Revolución cubana, Praga: Editorial de la Universidad Carolina, 2018.

5. La primera publicación en ruso apareció en 1995, Raby svobody $v$ literaturnykh arkhivakh KGB. Al año siguiente se publicó una versión en inglés.

6. Esta parte de la trilogía apareció primero en inglés en 1997, The KGB's Literary Archive; luego en español, y finalmente en ruso, Prestuplenie bez nakazaniya. Dokumentalnye povesti en el 2007.

7. Aunque los años más cruentos de la purga estalinista fueron 1937 y 1938, esta realmente no terminó sino hasta con el asesinato de León Trotski en agosto de 1940.

8. Véase "Great Purge", en History.com: <https://www.history.com/topics/russia/great-purge>, y Shentalinski, Crimen sin castigo, nota al pie No. I, página 402.

9. "Sus resultados se guardaron en el más absoluto secreto y sólo se publicaron en su totalidad en 1996, tras la perestroika. Había razones para esconderlos” (Shentalinski, 2007: p.406-407).

10. Leonid Kanneguíser fue ejecutado en septiembre de 1918, en Petrogrado (actual San Petersburgo); era poeta, judío, y tenía solo 22 años de edad. Kanneguíser asesinó a Moiséi Solomónovich Uritski, líder chequista, comisario del Pueblo de Asuntos Interiores de la Región Norte y presidente de la Checa [Comisión Extraordinaria, la primera de las organizaciones de inteligencia política y militar soviética, creada el diciembre de 1917] de Petrogrado, y como el 
poeta, era judío. El caso de Kanneguíser era el No. 196, y tenía once tomos. Al hacer su confesión, el poeta afirmó que decidió matar a Uritski por su presunta responsabilidad en fusilamientos masivos. Respecto al ambiente de esa época, Marina Tsvietáieva escribiría: “Estábamos sentados y leíamos versos. Los últimos versos sobre las últimas pieles junto a las últimas chimeneas... Unos venden el alma por tener las mejillas sonrosadas, otros dan el alma por sonidos celestiales. Todos pagaron. Seriozha y Lenia con la vida, Gumiliov, con la vida, Yesenin, con la vida, Kuzmín y Ajmátova, y yo con la cadena perpetua en mí, en esta fortaleza más elevada que la de Pedro y Pablo" (Shentalinski, 2007: p.107-108).

11. Gracias a la búsqueda en los archivos de la KGB, Shentalinski fue capaz de determinar la fecha exacta de la muerte de Gumiliov, y acabar así con las imprecisiones que históricamente había habido al respecto (Shentalinski, 2007: p. 270).

12. El título de esta sección es una glosa al libro de Graham Greene que le sirve de punto de partida a Ponte para la escritura.

13. "Los archivos de la policía secreta de Alemania Oriental habían sido abiertos a todo el que deseara investigar su propio caso en ellos" (Ponte, 2007: p.214).

14. En la película Operation Finale, del año 2018, dirigida por Chris Weitz, se narra la captura de Adolf Eichmann en 1960 por parte de un grupo de agentes de Mossad en Argentina, donde el alemán estaba viviendo con una identidad falsa.

15. Véase The Guardian, 25 March 2018: <https://www.theguardian.com/books/2018/ mar/25/my-mother-was-a-cold-war-spy-hungary-novelist-andras-forgach>

16. No haremos el recuento del archiconocido caso Padilla, pero baste recordar que las polémicas empezaron cuando Heberto Padilla criticara en El caimán barbudo el espacio dado por esa revista a Pasión de Urbino, de Lisandro Otero, y la no mención de Tres tristes tigres, de Cabrera Infante, que se había alzado con el Premio Biblioteca Breve de la editorial Seix Barral, por el que también compitió Otero. Mientras, Padilla concursaba en el Premio de Poesía "Julián del Casal" de la UNEAC con Fuera de juego, que ganara en 1968 -el poemario le hace un guiño a Pasternak, al usar un verso suyo como lema: “" Vivir la vida no es cruzar un campo"-. Como ya se sabe, Padilla terminó en prisión primero, y luego haciendo declaraciones inculpatorias al más puro estilo estalinista. Ya lo había advertido la escritora soviética Margarita Aliguer de visita en La Habanaa fines de 1968, respecto a los ataques en el Verde Olivo: "Con artículos iguales a esos comenzaron las purgas de Stalin". (Véase Manuel Díaz Martínez, "El caso Padilla: crimen y castigo (recuerdos de un condenado)").

17. Véase Ibrahim Hernández Oramas. "El acento Ponte. Una conversación”. Rialta, septiembre de 2018: <http://rialta-ed.com/acento-ponte/>

18. Iosif Brodsky, premio Nobel de Literatura en 1987, fue expulsado de la Unión Soviética en 1972. En 1964 -en pleno crepúsculo del deshielo- había sido condenado a 18 meses de prisión por "parásito". La pena le fue conmutada en 1965. Según Ponte, Abel Prieto intentaba, con este recado, "bajarle los humos, que no se fuera a creer cosas". (Véase Hernández Oramas, 2018: Web.)

19. Como se recordará, el KGB (Comité de Seguridad del Estado) funcionó entre 1954 y 1991, y fue una sucesora directa del NKVD (el Comisariado del Pueblo para Asuntos Internos, encargado de las Gulags y de las milicias -otro de los muchos órganos de seguridad del estado del gobierno de los Soviets)

20. Véase "Vitali Shentalinski destapa la tercera caja negra del KGB. Crimen sin castigo cierra su estudio sobre la represión de intelectuales en la URSS”. <https://elpais.com/diario/2007/12/04/ cultura/1196722803_850215.html>

21. Véase Jorge Wejebe Cobo: "El arte abstracto, Nikita Jruschov y la CIA": "Los organizadores de la exposición, nerviosos, la clausuraron ese mismo día y los artistas abstractos no pudieron celebrar con champaña, ni posar para los fotógrafos y fueron 
excluidos de la vida cultural en el país por juzgar la realidad por el 'olor de las letrinas', como dijera también el mandatario soviético en un encuentro con creadores en 1963." Por otra parte, los sucesos relacionados con la exhibición y posteriores acontecimientos están estrechamente vinculados con Cuba. La idea de exhibir las obras en la galería Manege surgió después de que a Anastas Mikoyan le preguntaran, durante su visita a la isla, sobre una exposición de artistas abstractos en Moscú. Mikoyan, hay que recordar, fue el primer oficial soviético que visitó Cuba después de 1959, y quien hizo posible la firma de acuerdos comerciales entre la Cuba y la URSS, en particular el de la exportación de petróleo soviético a cambio de azúcar cubano.

22. Inaugurado en 1989 como Museo Central de los Órganos de la Seguridad del Estado; y rebautizado en 1991, como Museo del Ministerio del Interior; y en 2017, con su actual nombre.

23. Véase <https://www.ecured.cu/Memorial_de_la_Denuncia>

24. El libro nunca ha sido publicado en Cuba.

\section{RESÚMENES}

El mismo año en que apareció la traducción al español de un libro sobre los archivos literarios de la KGB, Crimen sin castigo, de Vitali Shentalinski, en el 2007, también se lanzó en España otro libro sobre un tema análogo: La fiesta vigilada, de Antonio José Ponte. Y no podemos pensar sino en la coincidencia de estas publicaciones que, aunque desde posturas narrativas diferentes, trazan el camino de la censura literaria en dos países y sistemas sociopolíticos que compartieron más de una similitud. Este ensayo busca explorar los mecanismos de represión literaria implementados en ambos países tomando como punto de partida la literatura censurada de la que dan cuenta los dos libros mencionados, principalmente.

En 2007 apparait la traduction espagnole d'un livre sur les archives littéraires du KGB, Crimen sin castigo de Vitali Shentalinski, et en même temps est publié en Espagne, un autre livre sur un thème similaire : La fiesta vigilada, d'Antonio José Ponte. . Et l'on ne peut que penser à la coïncidence de ces publications qui, bien qu'à partir de positions narratives différentes, tracent le chemin de la censure littéraire dans deux pays et deux systèmes sociopolitiques qui partagent plus d'une similitude. Cet article cherche à explorer les mécanismes de répression littéraire mis en œuvre dans les deux pays, en prenant comme point de départ la littérature censurée qui est rapportée principalement par les deux livres mentionnés..

\section{ÍNDICE}

Mots-clés: censure et autocensure littéraire, archives, socialisme, répression et surveillance, dissidence, punition.

Palabras claves: censura y autocensura literaria, archivo, socialismo, represión y vigilancia, disidencia, castigo. 


\section{AUTOR}

\section{DAMARIS PUÑALES ALPIZAR}

Profesora Asociada de Estudios Hispanos y Presidenta del Departamento de Lenguas y Literaturas Modernas de Case Western Reserve University. Estudió Periodismo en la Universidad de La Habana y ha trabajado como periodista en Cuba, Belice y México. En Belice, fundó Conexión, el primer periódico bilingüe y transfronterizo. En México, fue corresponsal de medios de comunicación regionales y nacionales. dxp204@case.edu 